\title{
Uso del condón en personas de 18-45 años de la zona norte del estado de Veracruz
}

Condom use in people aged 18-45 in the northern part of the state of Veracruz

Martínez Díaz Nazaria ${ }^{\circledR}$, Zepeta Hernández David ${ }^{1}$, Gámez Velázquez Sofia ${ }^{2}$, Vargas Zaleta Nimbe Eunice $^{2}$, Isabel Miranda Landa Isabel ${ }^{2}$

${ }^{1}$ Docente de tiempo completo de la Facultad de Enfermería de la Universidad Veracruzana Región Poza Rica-Tuxpan, México, ${ }^{2}$ Docente por asignatura de la Facultad de Enfermería de la Universidad Veracruzana Región Poza Rica-Tuxpan, México, ${ }^{2}$ Docente por asignatura de la Facultad de Psicología de la Universidad Veracruzana Región Poza Rica-Tuxpan, México, ${ }^{2}$ Docente por asignatura de la Universidad Veracruzana Intercultural de la Universidad Veracruzana.

Autor para correspondencia: nmartinez@uv.mx

Recibido: 05/08/2019

Aceptado: 23/12/2019

\section{RESUMEN}

El VIH es catalogado como pandemia por el incremento de casos de infección, según las Organización de Naciones Unidas, en el 2016 en el mundo había 36.7 millones de personas con VIH, el porcentaje mayor es de hombres. El uso del preservativo masculino es una de las prácticas menos empleadas por los jóvenes en las relaciones sexuales, a pesar de que es considerado el principal método para prevenir enfermedades de transmisión sexual, incluido el VIH/SIDA. Estudio descriptivo, transversal con muestreo no probabilístico por conveniencia, participaron 486 participantes. Se aplicó el instrumento denominado información confidencial con 19 ítems de opción múltiple y 1 ítem de pregunta abierta. El $67 \%$ de las personas encuestadas fueron mujeres, el $21 \%$ contestó que usa condón a veces en sus relaciones sexuales, el mismo porcentaje contestó que casi siempre y el $18 \%$ dijo que casi nunca usa condón.

Palabras claves: Prevalencia, Condones, VIH, Pandemias.

\begin{abstract}
HIV is listed as a pandemic because of the increase in cases of infection, according to the United Nations, in 2016 in the world there were 36.7 million people with HIV, the highest percentage being men. The use of the male condom is one of the least used practices by young people in sexual relations, although it is considered the main method to prevent sexually transmitted diseases, including HIV / AIDS. Descriptive, cross-sectional study with non-probabilistic sampling for convenience, 486 participants participated. The instrument called confidential information was applied with 19 multiple choice items and 1 open question item. $67 \%$ of the people surveyed were women, $21 \%$ answered that they use condoms sometimes in their sexual relations, the same percentage answered that almost always and $18 \%$ said they almost never use a condom.
\end{abstract}

Keywords: Prevalence, Condoms, Pandemics, HIV. 


\section{INTRODUCCIÓN}

La Organización de las Naciones Unidas (ONU), en el marco de los objetivos de desarrollo del milenio señala que, en el año 2017 había 36.9 millones de personas viviendo con el Virus de Inmunodeficiencia Humana (VIH), alrededor de 1.8 millones de personas contrajeron la infección y 77.3 millones se han infectado con el VIH desde el inicio de la epidemia. Así mismo, menciona que a nivel mundial las adolescentes y las mujeres jóvenes enfrentan desigualdades de género, exclusión, discriminación y violencia, lo que las pone en mayor riesgo de contraer el VIH. También afirma que el Sindrome de Inmunodeficiencia Adquirida (SIDA) es ahora la principal causa de muerte entre los adolescentes de 10 a 19 años en África y la segunda causa más común de muerte entre los adolescentes de todo el mundo (ONU, 2015)

El VIH en la actualidad se le ha catalogado como pandemia debido al incremento de casos de infección, de acuerdo a al Programa Conjunto de las Naciones Unidas (ONUSIDA) sobre el VIH/SIDA había en el año 2016 en el mundo 36.7 millones de personas con VIH, donde el porcentaje mayor es de hombres, tan solo en el continente africano 19.4 millones de habitantes viven con la enfermedad y el $43 \%$ presenta un número total de nuevas infecciones, siendo este continente sudafricano quien posee el no honroso primer lugar en infecciones de VIH (ONUSIDA, 2017)

ONUSIDA en 2017 da información sobre el estado que guarda América Latina y refiere que: 1,8 millones de personas en 2017 vivían con el VIH las personas más vulnerables en tener VIH son hombres que representan el 1.1 millón portadores de VIH incluyendo los 40.000 de niñas adolescentes y mujeres jóvenes, la incidencia de morbilidad fue de aproximadamente 36.000 personas y en niños se registraron 1.800 casos de nuevas infecciones por VIH.

La mayor parte de la población mexicana se encuentra en el rango de edad entre 16 y 20 años, a nivel mundial este grupo de población ocupa el segundo lugar con más Enfermedades de transmisión sexual (ETS) entre ellas el VIH-Sida constituyéndose en un problema de salud pública no únicamente por el número de personas afectadas sino también por las repercusiones físicas, psicológicas y sociales que desencadenan en la vida de las personas que las padecen. Según estimaciones conjuntas, realizadas por Onusida-Censida, a finales de 2014 existían 190 mil personas viviendo con VIH-Sida. La prevalencia de VIH en la población de 15-49 años fue del 0.2 \%, lo que significa que dos de cada mil personas de esas edades estaban viviendo con el VIH ([Centro Nacional para la Prevención y Control del VIH y el SIDA] CENSIDA, 2015)

CENSIDA(2018) reporta que Veracruz tiene el primer lugar en mortalidad femenina a causa de SIDA;4 por cada cien mil habitantes y segundo en masculina 14.7 por cada cien mil habitantes, además de ubicarse también en primer lugar por muertes maternas con VIH aportando el 15\% del total nacional.

En México, el año 2011, el 93\% de los nuevos casos de VIH/Sida en jóvenes de 15 a 29 años se infectaron por la vía sexual, seguido del grupo de 30 años con un $91.2 \%$ de infecciones vía sexual. En 2018 cada día 41 personas se infectaron con VIH esta cifra es mayor que en 2017 donde cada día 33 personas contrajeron el virus lo que permite plantear que la actividad sexual se llevó a cabo sin uso del condón o este se usó de manera incorrecta (CENSIDA, 2018) Las relaciones sexuales que contribuyen a la diseminación de la infección de VIH son 
aquellas en las que no se usa protección, de ahí que el incremento en el uso del condón es una medida de intervención fundamental para la reducción de la epidemia (Staines, 2009).

López (2003) menciona que las conductas tienen una connotación más individual y las prácticas se enmarcan en lo común o compartido y enfatiza en las consecuencias negativas que conllevan tanto las prácticas como las conductas de riesgo que se reflejan en los 35 millones de infectados que reporta el programa de naciones unidas sobre el sida, en la que la población más vulnerable son los adolescentes y jóvenes entre los 15 y los 24 años y puntualiza que tener relaciones sin condón o habiendo consumido licor o la promiscuidad hacen más vulnerables a las personas.

La utilización o no del condón durante la relación sexual no solamente depende de las características personales, dado que este es un fenómeno multifactorial que tiene implicaciones de orden social. El uso del preservativo masculino es una de las prácticas menos empleadas por los jóvenes en las relaciones sexuales, a pesar de que es considerado el principal método para prevenir enfermedades de transmisión sexual, incluido el VIH/SIDA, solo el $20 \%$ de los hombres y el $17.2 \%$ de las mujeres dijo haber usado condón en el último año (Castañeda, Ortega, Reyes, Segura y Morón, 2009).

Entre las razones para no usar condón, está la falsa idea de que no se adquieren las Enfermedades de transmisión sexual (TS), otro argumento es la asociación del uso del condón con relaciones extramaritales, prostitución y promiscuidad además de la afirmación de que usar condón disminuye el placer sexual (Soto, 2006).

Ante el panorama mundial de ETS, la OMS dentro de su marco estratégico para la prevención de VIH y de los embarazos no planeados 2011-2015 ha sugerido que se debe usar condón en todas las relaciones sexuales que incluyan penetración y este se debe usar sin importar si se trata de una pareja estable o no.

En el área de la salud, el preservativo masculino continúa siendo el método ideal para la prevención de Enfermedades de Transmisión Sexual (ETS) y se ha descrito como el factor que disminuye la probabilidad de adquirir estas enfermedades; por lo que el uso constante del preservativo es un método importante para la prevención y la propagación de Infecciones de Transmisión sexual. La información oportuna, educación sexual y enseñanza del uso correcto del preservativo, así como la eliminación de barreras para que los adolescentes adquieran los preservativos, son medidas que contribuyen a disminuir las ETS.

La orientación debe encaminarse a eliminar los mitos que existen sobre el uso del preservativo y centrarse en los importantes beneficios para la salud. Los preservativos son un elemento crucial para un enfoque integral y sostenible de la prevención del VIH y otras infecciones de transmisión sexual (ITS) y son eficaces para evitar embarazos no deseados; éstos proporcionan una barrera impermeable para partículas del tamaño del esperma y los patógenos de la ITS, incluido el VIH. Si se utiliza en forma sistemática y correcta, los preservativos son muy eficaces para prevenir la transmisión sexual del VIH (Martínez, 2014).

El uso sistemático del condón si protege; sin embargo, el uso adecuado, pero no sistemático no protege completamente. En un estudio realizado en 563 parejas heterosexuales estables de personas con VIH/SIDA, 24 de ellas no se infectaron al usar sistemáticamente el condón, pero si se infectaron 44 que lo usaron de manera no sistemática. En todas las parejas que se infectaron influyo de manera importante la ingestión de alcohol en la decisión de los varones 
para no utilizar el condón. Se encontró que la transmisión del virus en un contacto sexual sin protección fue en hombres de $1 / 286$ y en mujeres de 1/350 (Del Rio, 2017).

De acuerdo al centro para el control y prevención de enfermedades, el uso correcto y constante de los condones de látex para los hombres puede reducir (aunque no eliminar) el riesgo de transmisión de las enfermedades de transmisión sexual (ETS). Para lograr la máxima protección, los condones se deben usar permanentes y de forma correcta, ya que el uso no constante de los condones puede conllevar a la transmisión de ETS (CENSIDA, 2014).

Una de las medidas que se les proponen a los adolescentes para la prevención de enfermedades de transmisión sexual principalmente el VIH//SIDA es el uso correcto del condón o preservativo en virtud de que se considera un método con un alto grado de confiabilidad para la protección de enfermedades de transmisión sexual, de ahí la importancia de sensibilizar a los jóvenes acerca del uso de condón como una estrategia necesaria e imprescindible para la prevención de ITS (Martínez, 2014).

\section{MATERIALES Y MÉTODOS}

Estudio descriptivo y transversal, la población se conformó por personas de 18 a 45 años, la muestra estuvo constituida por 486 personas de ambos sexos. El muestreo fue no probabilístico por conveniencia y la recolección de datos fue en el periodo febrero a diciembre 2018 .

Los criterios de inclusión fueron aquellas personas que aceptaron participar voluntariamente firmando el consentimiento informado previa orientación sobre la importancia de la prevención de Enfermedades de Transmisión sexual (ETS). La encuesta utilizada fue el cuestionario denominado Información Confidencial y está conformado por diecinueve ítems de opción múltiple y un ítem de pregunta abierta. Los datos obtenidos de la investigación fueron tabulados en el programa SPSS versión 22.0, haciendo uso de la estadística descriptiva para obtener frecuencias y porcentajes.

El estudio se apegó a las disposiciones generales de la Ley General de Salud en materia de investigación para la salud (Secretaria de Salud, 2012) específicamente en los apartados que se refieren a la garantía social de derecho y a la protección de salud en materia de investigación bajo estricto consentimiento informado de los participantes.

\section{RESULTADOS}

Se encuestaron 486 personas, el $67 \%$ mujeres y el $32 \%$ hombres principalmente. El $91.6 \%$ dijeron ser estudiantes y el $2.1 \%$ trabajador independiente. El $22.4 \%$ tiene bachillerato y el $72.4 \%$ es estudiante de licenciatura (Cuadro 1). El $23.3 \%$ inició su vida sexual entre los 15 y 16 años, el 35.8\% inicio entre 17 y 18 años. Respecto al uso de condón en las relaciones sexuales, el $21 \%$ contestó que a veces y en igual porcentaje dijo que casi siempre, el $18 \%$ casi nunca lo utiliza, únicamente el $17 \%$ mencionó utilizarlo siempre. En relación a infecciones de transmisión sexual, el $83 \%$ contestó que no ha cursado con ninguna infección, únicamente el $6 \%$ dijo haber padecido alguna infección sin especificar.

\section{DISCUSIÓN}

Staines (2009) afirma que las relaciones sexuales que contribuyen a la diseminación de la 
infección de VIH son aquellas en las que no se usa condón. Si se utiliza condón en forma sistemática y correcta son muy eficaces para prevenir la transmisión sexual del VIH (Martínez, 2014). En este estudio cuyo objetivo fue identificar el uso de condón como medida para prevenir el contagio de VIH/SIDA participaron 486 personas, 67\% mujeres, 32\% hombres y $1 \%$ Hombre trans (M-H). En el estudio de Piña (2010) participaron 394; 50.6\% mujeres y $49.4 \%$ hombres, y en el de Soto (2006) fueron 393 participantes 197 hombres y 196 mujeres.
En cuanto a la edad de inicio de las relaciones sexuales, se encontró que el $23.3 \%$ inicio a los 15 y 16 años, datos similares a los de Soto (2006) quien reporta que el 32.6\% inicio vida sexual entre los 15 y 16 años. Así mismo, el $35.8 \%$ mencionaron iniciar sus relaciones sexuales entre los 17 y 18 años, semejante a los resultados por Soto (2006) que encontró que el $32.4 \%$ inicio sus relaciones entre los 17 y 18 años.
Cuadro 1. Datos sociodemográficos

\begin{tabular}{lcc}
\hline & $\mathrm{f}$ & $\%$ \\
\hline Sexo & 328 & 67 \\
$\quad$ Mujeres & 156 & 32 \\
Hombres & 2 & 1 \\
$\quad$ Hombre Trans (M-H) & & \\
\hline Ocupación & 3 & 0.6 \\
$\quad$ Hogar & 10 & 2.1 \\
Independiente & 1 & 0.2 \\
Sexo comercial & 8 & 1.6 \\
Personal de salud & 6 & 1.2 \\
Sin empleo & 445 & 91.6 \\
Estudiante & 10 & 2.1 \\
Otro & 3 & 0.6 \\
No respondió & & \\
Escolaridad & 1 & 0.2 \\
Analfabeta & 1 & 0.2 \\
Primaria-Secundaria & 109 & 22.4 \\
Bachillerato & 352 & 72.4 \\
Licenciatura & 13 & 2.7 \\
Postgrado & 10 & 2.1 \\
No respondió & & \\
\hline
\end{tabular}




\section{Cuadro 2. Edad de inicio en relaciones sexuales}

\begin{tabular}{ccc}
\hline Rango de edad & $\mathrm{f}$ & $\%$ \\
\hline $7-12$ años & 3 & 0.6 \\
$13-14$ años & 17 & 3.5 \\
$15-16$ años & 113 & 23.3 \\
$17-18$ años & 174 & 35.8 \\
$19-21$ años & 65 & 13.4 \\
$22-30$ años & 11 & 2.3 \\
No respondió & 103 & 21.2 \\
\hline
\end{tabular}

Fuente: Directa

Respecto a la frecuencia del uso de condón en las relaciones sexuales, el $21 \%$ dijo que a veces y casi siempre respectivamente, el $18 \%$ casi nunca, el $7 \%$ nunca y el $17 \%$ siempre usa condón. Resultados que difieren con Piña (2010) en cuyo estudio reporto que el $45.4 \%$ usa condón la mayoría de las veces, el $18.8 \%$ pocas veces, $27.1 \%$ siempre y $4.6 \%$ nunca usa condón. También son muy diferentes a los datos de Soto (2006) quien reportó que el 56\% de los participantes no uso condón en la primera relación sexual y que el $46.9 \%$ de las mujeres no usaron condón en los últimos 6 meses. Entre las razones para no usar condón, está la falsa idea de que no se adquieren las infecciones de transmisión sexual (ITS), otro argumento es la asociación del uso del condón con relaciones extramaritales, prostitución y promiscuidad además de la afirmación de que usar condón disminuye el placer sexual (Soto, 2006).

Cuadro 3. Uso del condón en sus relaciones sexuales.

\begin{tabular}{lcc}
\hline & $\mathrm{f}$ & $\%$ \\
\hline Nunca (0-10) & 34 & 7 \\
Casi nunca (1-3 de 10) & 87 & 18 \\
A veces (4-6 de 10) & 103 & 21 \\
Casi siempre (7-9 de 10) & 102 & 21 \\
Siempre (10 de 10) & 82 & 17 \\
No respondió & 78 & 16 \\
\hline
\end{tabular}

Fuente: Directa 
Cuadro 4. Infección de transmisión sexual en los últimos 2 años.

\begin{tabular}{lcc}
\hline & $\mathrm{f}$ & $\%$ \\
\hline Sí & 27 & 6 \\
No & 406 & 83 \\
No sé & 37 & 8 \\
No respondió & 16 & 3 \\
\hline
\end{tabular}

Fuente: Directa

\section{CONCLUSIONES}

El uso del preservativo masculino es una de las prácticas menos empleadas por los jóvenes en las relaciones sexuales, a pesar de que es considerado el principal método para prevenir enfermedades de transmisión sexual, incluido el VIH/SIDA.

El conocimiento de los comportamientos sexuales de adolescentes y adultos jóvenes es muy importante porque da la pauta para implementar intervenciones eficaces que conlleven a la obtención de resultados beneficiosos para este grupo de población, sin perder de vista que el componente sexual es inherente al propio desarrollo del ser humano por lo que se debe manejar con responsabilidad para evitar contraer una enfermedad de transmisión sexual o embarazos no planeados.

\section{LITERATURA CITADA}

Aids Healtcare Foundation. (2019). Conoce AHF. Recuperado de: https://pruebadevih.com.mx/conoce-ahf/

Bahamón, M. J., Vianchá, M. A., y Tobos, A. R. (2014). Prácticas y conductas sexuales de riesgo en jóvenes: una perspectiva de género. Psicología desde el Caribe, 31(2), 327-353. https://doi.org/10.14482/psdc.31.2
Cable News Network Español. (2015). ¿Traspasa un condón el virus del VIH? La respuesta a esta y otras 5 preguntas sobre los preservativos. Disponible en: https://cnnespanol.cnn.com/2018/07/26/con don-virus-vih-mitos-verdades-preguntasrespuestas/

Castañeda, O., Ortega, N., Reyes Y., Segura O., y Morón, L. (2009). Conocimientos, actitudes y prácticas en salud sexual y reproductiva, en Yopal, Casanare, Colombia, 2009. Investigaciones Andina, 11(19), 31-48.

Centro Nacional para la Prevención y Control del VIH y el Sida. (2018). La epidemia del VIH y el sida en México. Recuperado de: http://www.censida.salud.gob.mx/descarga s/epidemiologia/L_E_V_S.pdf

Centro Nacional para la Prevención y el Control del VIH y el Sida. (2015). La epidemia del VIH y SIDA en México. Recuperado de: http://www.censida.salud.gob.mx/descarga s/principal/la_epidemia_deVIHysidaMexic o.pdf

Del Rio, C.A., y Uribe, P. (1993). Prevención de enfermedades de transmisión sexual y SIDA mediante el uso del condón. Salud Pública de México, 35(5), 508-517. 
Departamento de Salud y Servicios Humanos de los Estados Unidos. Centros para el Control y la Prevención de Enfermedades. (2019). Los condones y las ETS: Hoja informativa para el personal de salud pública. Recuperado de: https://www.cdc.gov/condomeffectiveness/ docs/Condoms_and_STDS_spanish.pdf

López, N. (2003). Curso de educación afectivosexual (Vol. 1). Netbiblo.

Martínez, A. (2014). Cómo afectan los estereotipos de género a la sexualidad. Recuperado de: https://unaf.org/saludsexualparainmigrantes /como-afectan-los-estereotipos-de-generoa-la-sexualidad/

Martínez-Torres, J., Parada-Capacho, L. Y., y Castro-Duarte, Z. K. (2014). Prevalencia de uso de condón en todas las relaciones sexuales con penetración durante los últimos doce meses y factores asociados en estudiantes universitarios entre 18 y 26 años. Universidad y Salud, 16, 198-206. https://doi.org/10.29375/01237047.1962

Organización Mundial de la Salud. (2018). Objetivos de Desarrollo del Milenio (ODM). Recuperado de: https://www.who.int/es/news-room/factsheets/detail/millennium-developmentgoals-(mdgs)

Programa Conjunto de la Naciones Unidas sobre el VIH/SIDA. (2017). Datos. Recuperado de: https://www.unaids.org/es/topic/data

Soto, V. (2006). Factores asociados al no uso del condón: Estudio en adolescentes y adultos jóvenes de Chiclayo. In Anales de la Facultad de Medicina (Vol. 67, No. 2, pp. 152-159). UNMSM. Facultad de Medicina. https://doi.org/10.15381/anales.v67i2.1253

Uribe, J. I., Covarrubias, K. Y., y Andrade, Palos, P. (2008). La cultura sexual de los adolescentes colimenses aspectos característicos de la cultura local. Estudios sobre las culturas contemporáneas, 14(28), 61-95.

Villalobos, A., Allen, B., Hernandez, M., Suárez, L., De La Vara, E., y Castro, F. (2012). Uso de anticonceptivos y planificación familiar entre mujeres adolescentes y adultas: cerrando la brecha entre metas y realidades. Instituto Nacional de Salud Pública, 5, 41-56. 
Copyright (c) 2019 Nazaria Martinez Diaz, David Zepeta Hernández, S ofia Gámez Velázquez, Nimbe Eunice Vargas Zaleta y Maria Isabel Miranda L anda

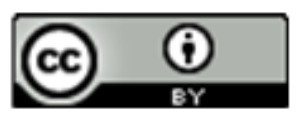

Este tex to está protegido por una licencia licencia CreativeCommons 4.0.

Usted es libre para Compartir — copiar y redistribuir el material en cualquier medio o formato-y Adaptar el documento — remezclar, transformar y crear a partir del material- para cualquier propósito, incluso para fines com erciales, siempre que cumpla la condición de:

Atribución: Usted debe dar crédito a la obra original de manera adecuada, proporcionar un enlace a la licencia, e in dicar si se han realizado cambios. Puede hacerlo en cualquier forma razonable, pero no de forma tal que sugiera que tiene el apoyo del licenciante o lo recibe por el uso que hace de la obra.

Resumendelicencia - Textocompletodelalicencia

Revista Científica Biológico Agropecuaria Tuxpan 7 (2)

ISSN: 2007-6940 